\title{
Pharmacokinetic-Pharmacodynamic (PK-PD) Modeling of Effect of Naringenin and Its Surface Modified Nanocarriers on Associated and Core Behaviors of Autism Spectrum Disorders (ASD)
}

\section{(ㄷ) (1) $(9)$}

\author{
Authors \\ Ranjana Bhandari, Jyoti K. Paliwal, Anurag Kuhad
}

\begin{abstract}
Affiliation
Pharmacology Research Laboratory, University Institute of Pharmaceutical Sciences, UGC-Centre of Advanced Study, Panjab University, Chandigarh, India
\end{abstract}

Key words

pharmacokinetic and pharmacodynamic (PK-PD), autism spectrum disorders (ASD), naringenin, glutathione, tween 80 , nanoparticles

received $\quad 13.05 .2019$

revised $\quad 10.07 .2019$

accepted $\quad 18.08 .2019$

Bibliography

DOI https://doi.org/10.1055/a-1001-2378

Published online: 2019

Planta Med Int Open 2019; 6: e41-e49

(c) Georg Thieme Verlag KG Stuttgart · New York

ISSN 2509-9264

Correspondence

Dr. Anurag Kuhad, MPharm, PhD, MNASc, MNAMS

Assistant Professor of Pharmacology

Pharmacology Research Laboratory

University Institute of Pharmaceutical Sciences UGC-Centre

of Advanced Study

Panjab University

160014 Chandigarh

India

Tel.: + 91/172/2541 142, Fax: + 91/172/2534 101

anurag_pu@yahoo.com; anurag.kuhad@pu.ac.in 丹upplementary Material for this article is available online at http://www.thieme-connect.de/products.

\begin{abstract}
The pharmacokinetic and pharmacodynamic (PK-PD) model was developed to describe the relationship between plasma/ brain concentration of naringenin and its nanocarriers with behavioral and biochemical alterations in a rat model of autism spectrum disorders (ASD). Behavioral parameters like sensorimotor dysfunction, hyperlocomotion, anxiety-like behavior, social interaction, and repetitive behavior were investigated by rotarod, actophotometer, open-field, reciprocal social interaction, and repetitive self-grooming test respectively. Naringenin was administered in doses $(25,50$, and $100 \mathrm{mg} / \mathrm{kg})$ and in the form of its uncoated and glutathione as well as tween 80 -coated PLGA nanocarriers $(25 \mathrm{mg} / \mathrm{kg}$ ) thrice daily (8 hourly). Sigmoid $\mathrm{E}_{\max }$ model was applied to study the relationship between the concentration of naringenin in plasma/brain and behavioral effects (in terms of sensorimotor dysfunction, locomotor activity, anxiety-like behavior, social interaction ability, repetitive behavior) as well as biochemical changes (plasma levels of TNF- $\alpha$, MMP-9, and HSP-70, and Pgp at BBB). Model parameters such as $\mathrm{E}_{0}$, $\mathrm{E}_{\max }$, and $\mathrm{EC}_{50}$ indicate that maximum effect occurred after administration of GSH-coated naringenin nanoparticles and the minimum effect occurred with the $25 \mathrm{mg} / \mathrm{kg}$ dose of unencapsulated naringenin. The $R^{2}$ value of 0.99 and small Akaike information criterion indicate the goodness of fit of the model. The PK-PD modeling done by sigmoid $\mathrm{E}_{\max }$ model showed a positive correlation between plasma/ brain drug concentration and neuroinflammatory markers as well as behaviors consistent with the ASD phenotype.
\end{abstract}




\section{LIST OF ABBREVIATIONS}

$\begin{array}{ll}\text { PK-PD } & \text { Pharmacokinetic and Pharmacodynamic } \\ \text { ASD } & \text { Autism Spectrum Disorders } \\ \text { PLGA } & \text { Poly(lactic-co-glycolic acid) } \\ \text { TNF-alpha } & \text { Tumour necrosis factor-alpha } \\ \text { MMP-9 } & \text { matrix metalloproteinases 9 } \\ \text { HSP-70 } & \text { Heat Shock Protein 70 } \\ \text { PgP } & \text { P-glycoprotein } \\ \text { BBB } & \text { Blood brain barrier } \\ \text { IL-6 } & \text { Interleukin-6 } \\ \text { NP } & \text { nanoparticle } \\ \text { PPA } & \text { Propanoic acid } \\ \text { GSH } & \text { Glutathione } \\ \text { NGN } & \text { Naringenin } \\ \text { IL- } \beta & \text { Interleukin-Beta }\end{array}$

\section{Introduction}

Autism spectrum disorders (ASD) include complex neurodevelopmental disorders associated with characteristic symptoms that manifest in children at $3 \mathrm{y}$ of age. These characteristic symptoms include impairments in social interaction and communicative skills as well as the presence of restrictive, repetitive, pervasive, and stereotypic behavior. In addition to the above, some co-morbidities like irritable nature, anxiety, aggression, cognitive deficits, hampered adaptive skills, and accompanied disorders like attention deficit hyperactivity disorder, epilepsy, and sensory processing disorder are also associated with ASD [1,2]. According to the National Institute of Mental Health, $2.41 \%$ of children in the US have ASD. Prevalence of ASD has been reported by the U.S. Center for Disease Control and Prevention to be 1 in 59 children in 2018 in comparison to 2010 reports of 1 in 88 . The World Health Organization reports of 2017 show that worldwide 1 in 160 children is suffering from ASD [3]. ASDs show significant skewness in occurrence in boys with a sex ratio of 4:1 [4-6]. ASD presents a complex integration of genetic, epigenetic, and environmental factors. It is a complex interaction between preexisting genetic factors and environmental factors that alter the functional capacity of the brain [6-10].

Apart from several behavioral and cognitive complications arising as a result of central nervous system dysfunction, there are various physiological co-morbidities associated with ASD that can also worsen the behavioral complications. Research and clinical studies indicated many physiological co-morbidities such as immune system deregulation, neuroinflammation, oxidative stress, mitochondrial dysfunction, and gastrointestinal complications [6, 11, 12]. The release of pro-inflammatory cytokines such as tumor necrosis factor-alpha (TNF- $\alpha$ ), IL-6, IL- $\beta$, and other triggers of neuroinflammation such as heat shock protein-70 (HSP-70) and matrix metalloproteinases-9 (MMP-9) as a result of the generation of oxidative stress and immune system activation is one of the components of the pathogenesis of ASD $[13,14]$.

Behavioral and gastrointestinal symptoms worsen in ASD children after intake of high carbohydrate containing propanoic acid (PPA) as a preservative $[15,16]$. PPA, a weak organic acid, can cause the release of inflammatory cytokines as well as depletion of endogenous antioxidants like glutathione (GSH) and superoxide dismutase as well as the elevation of lipid peroxidase leading to increased oxidative stress. Intracerebroventricular administration of PPA in adolescent rats induced ASD phenotype $[17,18]$. We have also validated this model in our lab with some modifications and evaluated the therapeutic potential of curcumin resveratrol and naringenin (NGN) [19-21]. We have observed the increase in markers of neuroinflammation such as TNF- $\alpha$, MMP-9, and HSP-70 in our previous studies as well as depletion of endogenous antioxidants as a result of oxidative stress that results in the development of ASD like core as well as associated behaviors.

( \pm )-Naringenin (5,7-dihydroxy-2-(4-hydroxyphenyl) chroman4-one) is a flavanone that is abundantly found in grapefruit as well as in oranges and tomato skin [22]. NGN has been found also to exert its antioxidant, antihyperlipidemic, antidepressant, antiproliferative, and anti-inflammatory effects [23-27]. Despite its therapeutic potential NGN's role clinically has been hampered as a result of its poor bioavailability, instability, and extensive first-pass metabolism before reaching the systemic circulation [28, 29]. In order to improve the bioavailability and enhance the brain uptake of NGN, we developed NGN-loaded PLGA nanoparticles in our laboratory and also coated these with reduced GSH and tween 80 in order to inhibit the P-glycoprotein (P-gp) efflux transporter. We evaluated their brain uptake, studied in vivo pharmacokinetics, and observed that there is an improvement in bioavailability of NGN and its enhanced uptake in the brain after surface coating of nanoparticles with GSH and tween 80 (our unpublished study).

We have explored the therapeutic potential of NGN as well as its coated and uncoated nanoparticles in the experimental paradigm of ASD [21].

The pharmacokinetic-pharmacodynamic (PK-PD) model is a prospective aid for efficient drug development as its usage can avoid high attrition rates of drugs from the market as a result of lack of efficacy and safety issues raised during clinical trials or postmarketing surveillance phase [30]. It is a promising tool in translational drug research that can predict about safety and efficacy of drugs on the basis of in vitro and in vivo studies. It can prove to be of help in optimization of dosage regimen especially for controlled release formulations in clinical trials, simulating, and optimizing of phase 3 clinical trial design and in early drug development [31]. PK-PD modeling is a useful tool that can connect PK and PD so that effect and time relationship occurring after the administration of a particular dose of a drug can be predicted from the dose-response relationship [32]. When pharmacodynamic parameters are not dependent on time and concentration of the drug is constant at the active site (i.e., steady-state has been achieved), then concentration and effect can be predicted utilizing the models such as the linear effect concentration model, log-linear effect concentration model, fixed-effect model, and $\mathrm{E}_{\max }$ and sigmoid $\mathrm{E}_{\max }$ model. Timedependent study of data shows the presence of hysteresis loop (i. e., there is some delay between the plasma concentration of drug at the site of action and its effect). The hysteresis loop is either clockwise or counterclockwise. The 2 non-steady-state models are the effect compartment model and physiological indirect response models. Modeling criteria depends on either the mode of administration of the drug or the dependence of pharmacodynamic pa- 
rameters on time. Hence, when a steady state is achieved after multiple dosing or long-term infusion, then steady-state models are used, but when a single dose of the drug is administered and pharmacodynamic parameters show a time-dependent relationship, then more complicated models are used such as those meant for the non-steady state. Simple and empirical models have limitation in their capability to predict the relationship between effect and concentration as they do not take into account the mechanism behind the delay in response. Thus, more mechanism-based models for PK-PD correlation are required that are based on a mechanism that a drug undergoes at the site of action and presents forth actual relationship between the concentration of drug and effect [3135].

With this background, we have designed this PK-PD study to establish a relationship between various concentrations of NGN in plasma and brain achieved via administration of various doses of unencapsulated as well as its uncoated and coated nanocarriers and their effect on various behavioral/biochemical alterations.

\section{Results}

Six groups of animals out of 7 groups, which were administered $1 \mathrm{M}$ PPA, were treated with NGN $(25,50$, and $100 \mathrm{mg} / \mathrm{kg})$ and with uncoated as well as GSH or tween 80-coated NGN-loaded PLGA nanoparticles $(25 \mathrm{mg} / \mathrm{kg}$ ). Different plasma concentrations (approximately equal to the minimum residual dose) of NGN were achieved on the $22^{\text {nd }}$ day, $8 \mathrm{~h}$ after the administration of the last dose on the $21^{\text {st }}$ day. The minimum plasma concentration of $(1482.8 \pm 0.22 \mathrm{ng} /$ $\mathrm{mL})$ was for NGN $(25 \mathrm{mg} / \mathrm{kg})$ and highest was for GSH-coated nanoparticles $(25 \mathrm{mg} / \mathrm{kg})(4185.3 \pm 0.62 \mathrm{ng} / \mathrm{mL})$. The plasma concentration of NGN for the group receiving NGN-PLGA nanoparticles $(3674.6 \pm 0.78 \mathrm{ng} / \mathrm{mL}$ ) was comparable to that of the unencapsulated drug $(100 \mathrm{mg} / \mathrm{kg})(3811.2 \pm 0.45 \mathrm{ng} / \mathrm{mL})$. Similarly, the concentration of NGN in the brain was minimum for the group receiving NGN $(25 \mathrm{mg} / \mathrm{kg})(314.62 \pm 0.18 \mathrm{ng} / \mathrm{mL})$ and highest was for the group receiving GSH-coated nanoparticles $(1296.28 \pm 0.45 \mathrm{ng} / \mathrm{mL})$. The concentration of NGN in brain for group receiving NGN-PLGA nanoparticles $(25 \mathrm{mg} / \mathrm{kg})(989.42 \pm 0.88 \mathrm{ng} / \mathrm{mL})$ was comparable to that of free NGN $(100 \mathrm{mg} / \mathrm{kg})(926.2 \pm 0.96 \mathrm{ng} / \mathrm{mL})$. Various pharmacological responses were observed such as time of fall (sensorimotor dysfunction), ambulations, rearing (locomotor activity), number of line crossings and entries into a center circle (anxietylike behavior), time spent in reciprocal social interaction, and repetitive self-grooming. PPA administration resulted in a decrease in time of fall $(21.6 \pm 0.8 \mathrm{~s})$ that was increased to $204.6 \pm 0.96 \mathrm{~s}$ after administration of GSH-coated NGN-loaded nanoparticles. Anxiety results in hyperlocomotion, as seen from a large number of rearings (100.2 \pm 2.5$)$, ambulations (168.4 \pm 0.9 ), number of line crossings (158.2 \pm 1.8$)$, and number of entries in center circle (58.6 \pm 1.6$)$. PPA administration (i. e., induction of ASD-like phenotype) also results in a decrease in time spent in social interaction $(89.3 \pm 0.45 \mathrm{~s})$ and increase in time spent in repetitive self-grooming (356.2 $\pm 0.75 \mathrm{~s})$. Maximum reduction was observed after administration of GSHcoated NGN-loaded nanoparticles and the minimum reduction was after administration of NGN (25 mg/kg). GSH NGN-NPs showed significant reduction in neuroinflammatory markers like TNF- $\alpha$ $(182.1 \pm 1.2 \mathrm{pg} / \mathrm{mL}$ to $6.2 \pm 2.0 \mathrm{pg} / \mathrm{mL}), \mathrm{MMP}-9(13.4 \pm 0.8 \mathrm{ng} / \mathrm{mL}$ to
$1.2 \pm 0.94 \mathrm{ng} / \mathrm{mL})$, and HSP-70 (492.8 $\pm 1.7 \mathrm{ng} / \mathrm{mL}$ to $17.2 \pm 2.8 \mathrm{ng} /$ $\mathrm{mL}$ ) in plasma. TNF- $\alpha$ levels in the brain also showed reduction after administration of GSH NGN-PLGA nanoparticles (1122.2 $\pm 1.5 \mathrm{pg} /$ $\mathrm{mL}$ to $28.4 \pm 1.5 \mathrm{pg} / \mathrm{mL}$ ). Efflux transporter (P-gP) at BBB was upregulated in PPA administered rats as observed from P-gp concentration $(58.3 \pm 0.8 \mathrm{ng} / \mathrm{mL}$ versus control reading of $43.98 \pm 1.75 \mathrm{ng} /$ $\mathrm{mL}$ ) in the brain homogenate. Maximum reduction in P-gp concentration was reported in $\mathrm{GSH}$-coated nanoparticles $(2.92 \pm 0.8 \mathrm{ng} /$ $\mathrm{mL}$ ) treated group.

To find out the relationship between PK and PD parameters, the results were analyzed using the sigmoid $E_{\max }$ model with the help of PK Solver 2.0 (Microsoft Excel Add-Ins program). The graphs showing predicted and observed responses at various concentrations for plasma ( $\triangleright$ Fig. 1) as well as the brain ( $\triangleright$ Fig. 2). Various PD parameters like $E_{o}$ (baseline effect when no concentration is present), $E_{\max }$ (maximum effect), $\mathrm{EC}_{50}$ (concentration at which $50 \%$ effect occurs), $Y$ (sigmoidicity factor), $R^{2}$ (regression coefficient), and Akaike information criterion (AIC) (measure of goodness of fit for the model) for various behavioral tests, neuroinflammatory markers, and efflux transporter described above have been given in $>$ Table $\mathbf{1 .}$

\section{Discussion}

The main aim for the development of PK-PD model of NGN and its nanocarriers was to understand the relationship between plasma and brain concentration of NGN and behavioral alterations such as social behavior, repetitive behavior, sensorimotor dysfunction, hyperlocomotion, and anxiety as well as neuroinflammatory markers such as TNF- $\alpha$, MMP-9, and HSP-70 and P-gP. Sigmoid $\mathrm{E}_{\max }$ model was used to establish a PK-PD correlation. PPA administration resulted in a decrease in time of fall $(21.6 \mathrm{~s})$, increase in number of rearings and ambulations (100.2 and 168.4), increase in number of line crossings and entries into center circle (158.2 and 58.6) indicating anxiety, increase in time spent in self-grooming (356.2 s), and decrease in social interaction time (89.3s) as well as increase in levels of neuroinflammatory markers such as TNF- $\alpha$, MMP-9, and HSP-70 and upregulation of efflux transporter, P-gp. $E_{0}$ values indicated the parameters after administration of PPA and before the beginning of treatment with NGN and its nanocarriers. These results are consistent with the scientific literature indicating about the effect of short-chain fatty acids such as PPA in generating neuroinflammatory cascade and causing alterations in behavior, biochemical, and molecular alterations in autistic patients [36-38]. Moreover, clinical findings also suggest an increase in the levels of neuroinflammatory markers such as TNF- $\alpha$, MMP-9, and HSP-70 and oxidative stress in autistic patients $[39,40]$. The results of sigmoid $\mathrm{E}_{\max }$ model showed that after administration of unencapsulated NGN $(25,50$, and $100 \mathrm{mg} / \mathrm{kg})$ as well as its coated and uncoated nanocarriers $(25 \mathrm{mg} / \mathrm{kg})$, maximum effect occurred after administration of GSH-coated NGN-loaded nanoparticles as indicated by $\mathrm{E}_{\max }$ values and minimum after administration of NGN (25 mg/kg) as maximum plasma and brain concentrations of NGN were achieved after administration of GSH-coated nanoparticles and minimum with NGN $(25 \mathrm{mg} / \mathrm{kg})$. Hence, after administration of different doses of NGN and its nanocarriers, there was an improvement in behavior and reduction in the levels of neuroinflam- 

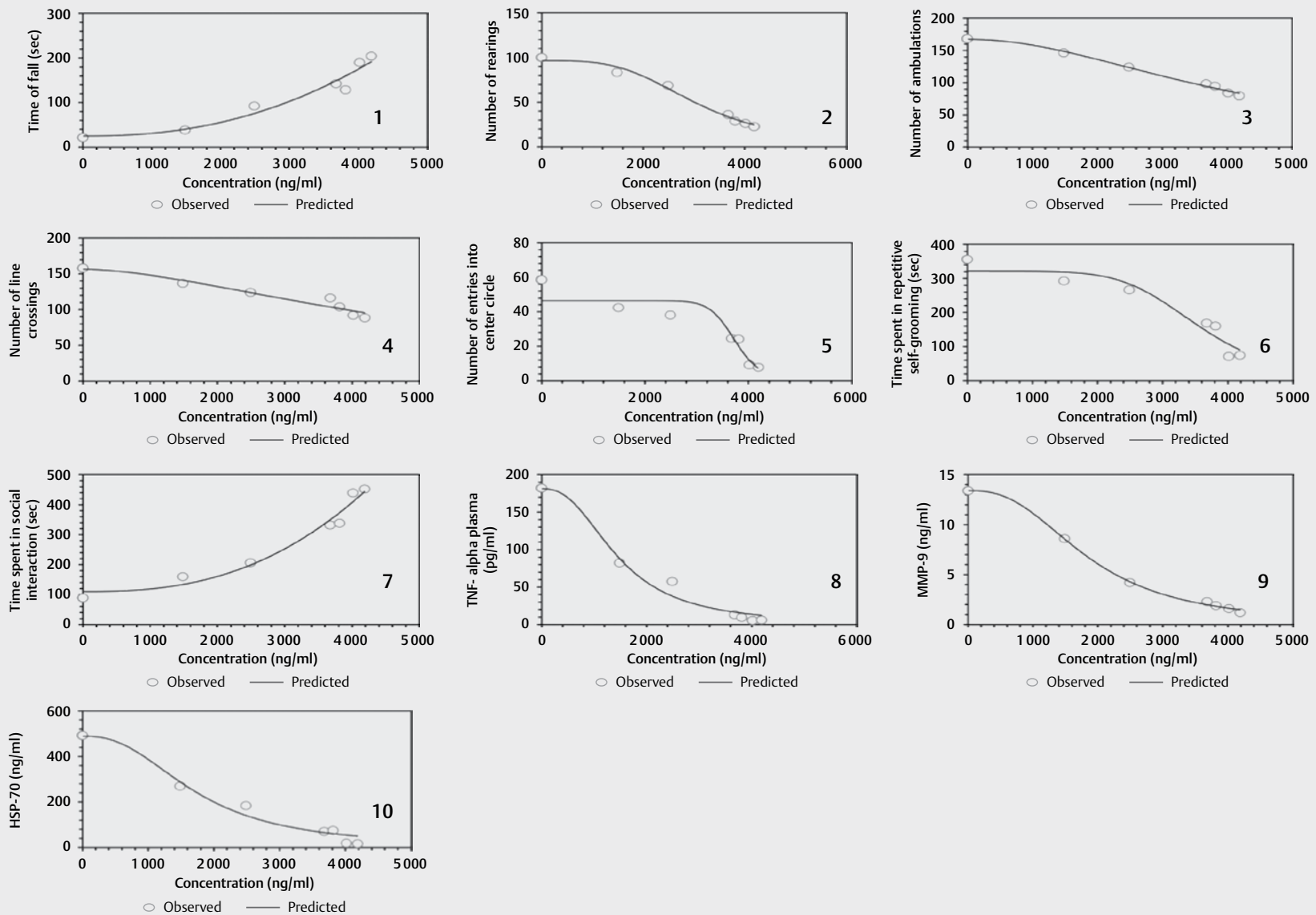

- Fig. 1 Sigmoid $E_{\max }$ model correlating various pharmacological responses and neuroinflammatory markers with plasma concentration of NGN after administration of NGN (25, 50, and $100 \mathrm{mg} / \mathrm{kg})$, NGN-PLGA-NPs $(25 \mathrm{mg} / \mathrm{kg})$, and GSH NGN-PLGA-NPs and Tween 80-NGN-PLGA-NPs. 1 Time of fall (s). 2 Number of rearings. 3 Number of ambulations. 4 Number of line crossings. 5 Number of entries in center circle. 6 Time spent in repetitive self-grooming. 7 Time spent in social interaction. 8 Levels of TNF- $\alpha$. 9 Levels of MMP-9. 10 Levels of circulating antibodies to HSP-70.

matory markers such as TNF- $\alpha$, MMP-9, and HSP-70 and P-gp by virtue of its neuroprotective effect as a result of its antioxidant action [41]. However, the effect was maximum as a result of braintargeted action of GSH-coated nanocarriers. The sigmoid $\mathrm{E}_{\max }$ model showed good fit as indicated from values of $\mathrm{R}^{2}$, which was 0.99 and showed the closeness of observed and predicted value (observed value of $\mathrm{E}_{\max }$ for number of line crossings was $88.6 \mathrm{~s}$ but the predicted value was 95.74). A similar pattern was observed for other effects. A small AIC value indicates the appropriateness of the model and goodness of fit of the data. Sigmoidity factor $(\gamma)$ is the curve-fitting parameter in the sigmoid $\mathrm{E}_{\max }$ model indicating the steepness of the concentration-effect relationship. Its values ranged from 1.31-21.4 (brain) and 1.68-14.95 (plasma). The maximum value of $\gamma$ was for TNF- $\alpha$ levels in the brain indicating a very steep sigmoid curve. The P-gp concentration in the Sigmoid $\mathrm{E}_{\max }$ model also indicated enhanced inhibition of these efflux transporters due to the presence of the coating. Hence, encapsulation of NGN in the nanoparticles as well as coating with GSH and tween 80 not only resulted in improved bioavailability but also resulted in brain targeting as a result of inhibition P-gp. The increase in plasma as well as brain concentration of NGN correlated with improve- ment in social interaction ability, repetitive behavior, sensorimotor dysfunction, and anxiety-like behavior after administration of coated nanoparticles $(25 \mathrm{mg} / \mathrm{kg}$ ) as compared to uncoated and even with the highest dose of NGN (i. e., $100 \mathrm{mg} / \mathrm{kg}$ ). Our results are in lines with those documented in the literature that indicated improvement in bioavailability after encapsulation of drug in nanoparticles and inhibition of P-gp efflux and enhanced brain uptake after coating with GSH and tween 80 [42-45].

Hence, the PK-PD modeling done by sigmoid $\mathrm{E}_{\max }$ model showed a positive correlation between plasma/brain drug concentration and neuroinflammatory markers as well as behaviors consistent with the ASD phenotype.

\section{Material and Methods}

\section{Animals and drugs}

Male Sprague-Dawley rats (250-280 g), 3-4 m old and bred in Central Animal House Facility of Panjab University, Chandigarh (India), were used. The rats were housed individually in cages and given free access to standard laboratory food (Ashirwad Industries) and 

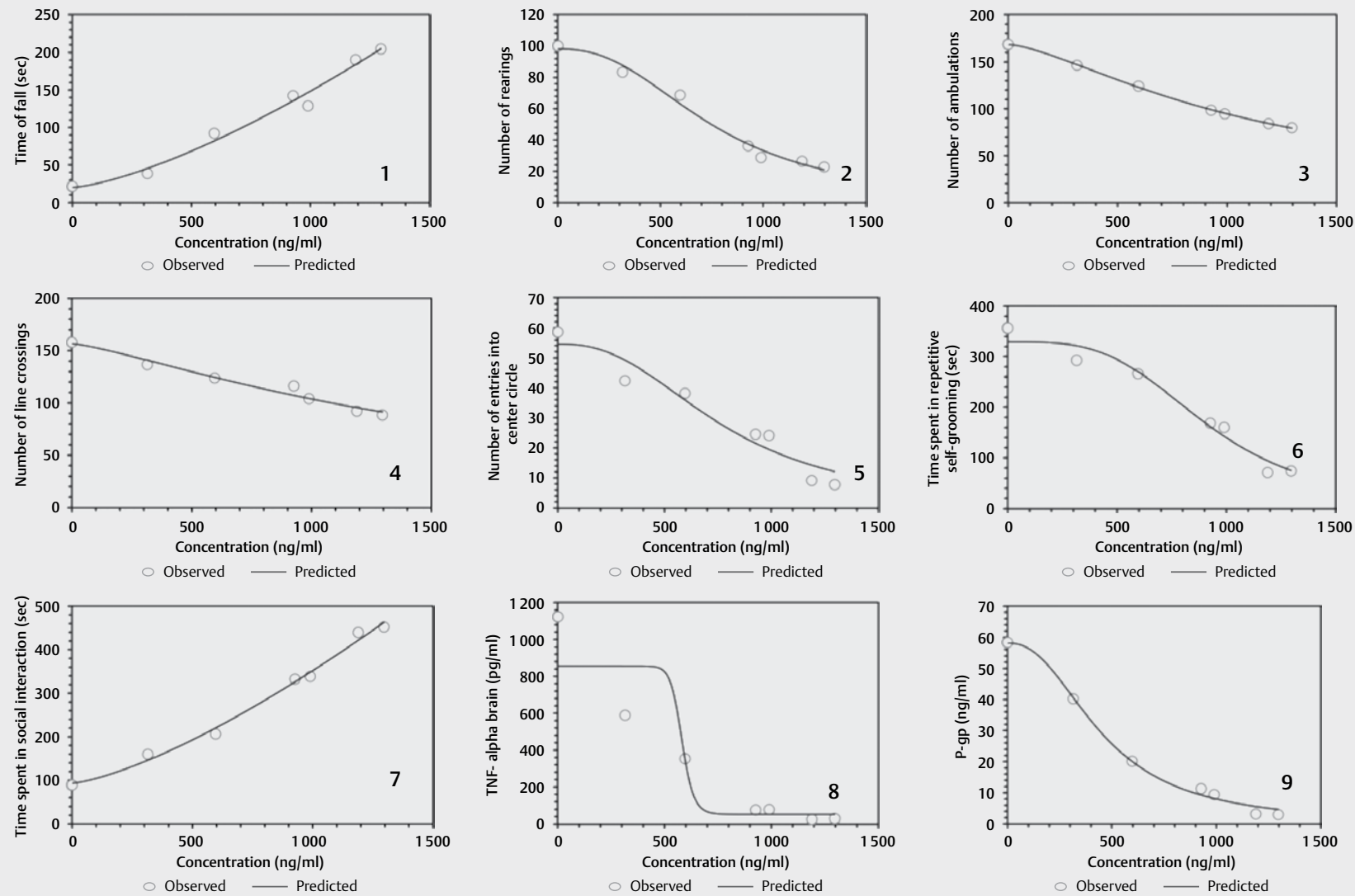

- Fig. 2 Sigmoid $\mathrm{E}_{\max }$ model correlating various pharmacological responses and P-gp concentration with a concentration of NGN in the brain after administration of NGN $(25,50,100 \mathrm{mg} / \mathrm{kg})$, NGN-PLGA-NPs $(25 \mathrm{mg} / \mathrm{kg})$, and GSH NGN-PLGA-NPs and tween 80-NGN-PLGA-NPs. 1 Time of fall (s). 2 Number of rearings. 3 Number of ambulations. 4 Number of line crossings. 5 Number of entries in center circle. 6 Time spent in repetitive selfgrooming. 7 Time spent in social interaction. 8 Levels of TNF- $\alpha$ (brain). 9 Concentration of P-gp.

water. The experimental protocol was approved by Institutional Animal Ethics Committee of Panjab University, Chandigarh (PU/45/99/CPCSEA/IAEC/2018/115) and was conducted according to Committee for the Purpose of Control and Supervision on Experiments on Animals (CPCSEA) guidelines for the use and care of experimental animals.

PPA, NGN (MW = 272.25, purity $\geq 98 \%$ HPLC), Resomer RG 502 H (Poly(DL-lactide-co-glycolide) (PLGA)), 50:50, MW = $7000-$ 17000 ), Kolliphor P 188 (poloxamer 188), polysorbate 80 (tween 80 ), and reduced GSH were purchased from Sigma Chemical Co. TNF- $\alpha$ ELISA and MMP-9 assay kits were purchased from R\&D Systems. Assay kits for HSP-70 and P-gp were purchased from Qayee Biotechnology-life sciences and Wuhan Sciences, respectively. All other chemicals used for biochemical estimations were of analytical grade.

\section{Preparation of NGN-PLGA uncoated as well as coated nanoparticles}

The NGN-PLGA nanoparticles were prepared by nanoprecipitation method reported by Fessi et al. [46] with minor modifications. NGNPLGA nanoparticles were further coated with reduced GSH and polysorbate 80 in order to enhance brain delivery. One percent poly- sorbate 80 coating over NGN nanoparticles was done as reported by Wilson et al. (2008) with minor modifications. While GSH-coated nanoparticles were prepared with minor modifications in the method reported by Geldenhuys et al. [45]. The nanoparticles were characterized for size, morphology, entrapment efficiency, and in vitro drug release. The average particle size of uncoated NGN nanoparticles was found to be $143.93 \pm 2.68 \mathrm{~nm}$ while GSH and tween 80 -coated nanoparticles were found to be $223.86 \pm 6.09 \mathrm{~nm}$ and $152.4 \pm 2.1 \mathrm{~nm}$, respectively (to-be published data).

\section{Study design}

ASD was induced in rats by administering an intracerebroventricular injection of 1M PPA according to the procedure of MacFabe et al. with some modifications and as in our published studies [19-21].

For the current study, rats were randomly selected and divided into 7 groups of 5 animals each. The first group was ASD induced group that received $1 \mathrm{M}$ PPA. The second, third, and fourth groups consisted of ASD-induced animals (administered with 1M PPA) treated with 25,50 , and $100 \mathrm{mg} / \mathrm{kg}$ (peroral) NGN administered thrice daily ( 8 hourly). The fifth, sixth, and seventh groups were administered with NGN-loaded PLGA nanoparticles (NGN-PLGA-NP), reduced GSH-coated NGN-loaded PLGA nanoparticles (GSH NGN- 


\begin{tabular}{|c|c|c|c|c|c|c|c|c|c|c|c|c|c|c|}
\hline 高 & & & & & & & & & 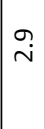 & $\mid \begin{array}{c}m \\
\infty \\
\infty \\
n\end{array}$ & 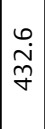 & $\stackrel{m}{i}$ & 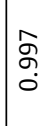 & $\stackrel{g}{\dot{\nu}}$ \\
\hline 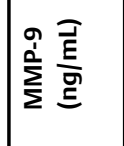 & & $\stackrel{n}{r}$ & $\stackrel{\dot{m}}{r}$ & $\begin{array}{l}m \\
\stackrel{m}{m} \\
\stackrel{n}{n}\end{array}$ & $\stackrel{0}{i}$ & જ़ & $\stackrel{\nabla}{\dot{m}}$ & & & & & & & \\
\hline 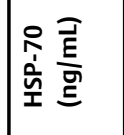 & & 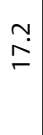 & $\begin{array}{l}\infty \\
\tilde{N} \\
\stackrel{+}{~}\end{array}$ & $\begin{array}{l}- \\
\infty \\
\infty \\
\dot{0} \\
-\end{array}$ & $\stackrel{\stackrel{n}{i}}{\sim}$ & 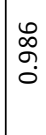 & $\frac{1}{\sigma}$ & & & & & & & \\
\hline 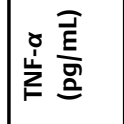 & & $\tilde{\omega}$ & $\begin{array}{l}\overline{\dot{D}} \\
\stackrel{\infty}{-}\end{array}$ & $\begin{array}{l}\text { ம் } \\
\stackrel{2}{m} \\
-\end{array}$ & $\stackrel{\stackrel{n}{\sim}}{\sim}$ & $\begin{array}{l}\mathscr{2} \\
\infty \\
0 \\
0\end{array}$ & กุ & & $\begin{array}{l}+ \\
\infty \\
\sim \\
\sim\end{array}$ & 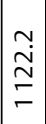 & 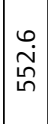 & $\stackrel{\dot{\sigma}}{\grave{N}}$ & ๙ิ & $\stackrel{n}{\sigma}$ \\
\hline 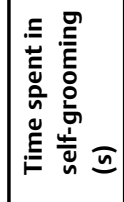 & & $\stackrel{m}{\sim}$ & $\mid \begin{array}{c}\sim \\
\stackrel{0}{ } \\
\stackrel{n}{m}\end{array}$ & $\begin{array}{l}\stackrel{\nabla}{0} \\
\stackrel{\infty}{\sim} \\
\stackrel{\sim}{m}\end{array}$ & in & 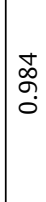 & $\begin{array}{l}0 \\
\dot{\infty} \\
0\end{array}$ & & $\stackrel{m}{\stackrel{p}{\sim}}$ & $\mid \begin{array}{c}n \\
\mathscr{0} \\
\stackrel{n}{n}\end{array}$ & 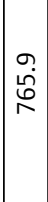 & $\stackrel{\stackrel{n}{n}}{m}$ & సু & $\begin{array}{l}0 \\
i \\
\sigma\end{array}$ \\
\hline 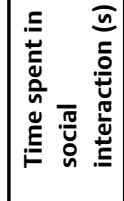 & & $\begin{array}{l}\stackrel{+}{i ்} \\
\text { ్ֶ }\end{array}$ & $\begin{array}{l}m \\
\infty \\
\infty\end{array}$ & \begin{tabular}{|l}
$\stackrel{n}{\alpha}$ \\
$\stackrel{g}{5}$ \\
$\bar{m}$
\end{tabular} & 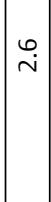 & 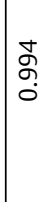 & ثึ่ & & 守 & $\begin{array}{l}m \\
\infty \\
\infty\end{array}$ & $\begin{array}{l}m \\
\stackrel{m}{\sigma} \\
\stackrel{2}{\kappa}\end{array}$ & $\stackrel{+}{-}$ & $\begin{array}{l}\infty \\
\text { مे } \\
\text { ○े }\end{array}$ & $\overline{\dot{\varphi}}$ \\
\hline 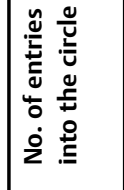 & & $\stackrel{\infty}{r}$ & $\begin{array}{l}0 \\
\infty \\
\infty \\
\llcorner\end{array}$ & \begin{tabular}{|l|}
0 \\
$\infty$ \\
0 \\
0 \\
$m$ \\
$m$
\end{tabular} & 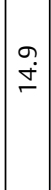 & $\begin{array}{l}\hat{\mathscr{o}} \\
\text { ọ }\end{array}$ & 㝘 & & $\stackrel{\infty}{\sim}$ & $\begin{array}{l}0 \\
\infty \\
\infty \\
i n\end{array}$ & \begin{tabular}{|c|} 
\\
\\
$\dot{\sigma}$ \\
\end{tabular} & $\stackrel{\stackrel{n}{\sim}}{\sim}$ & $\begin{array}{l}\text { م } \\
\text { م్ } \\
0\end{array}$ & $\stackrel{\infty}{\stackrel{\sim}{~}}$ \\
\hline 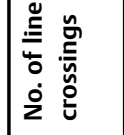 & & $\begin{array}{l}0 \\
\infty \\
\infty\end{array}$ & 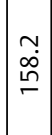 & 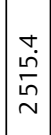 & $\stackrel{?}{-}$ & જ̆ & 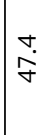 & & $\begin{array}{c}0 \\
\infty \\
\infty\end{array}$ & $\mid \begin{array}{c}n \\
\infty \\
\sim \\
\sim \\
\end{array}$ & $\begin{array}{c}+ \\
\stackrel{1}{0} \\
6\end{array}$ & $\stackrel{m}{-}$ & $\begin{array}{l}\infty \\
\text { مे } \\
\text { ○े }\end{array}$ & $\begin{array}{l}0 \\
\dot{\sigma} \\
\dot{\sigma}\end{array}$ \\
\hline 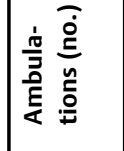 & & $\begin{array}{l}\stackrel{\infty}{r} \\
\stackrel{r}{ }\end{array}$ & $\begin{array}{l}\dot{\nabla} \\
\dot{\infty} \\
\stackrel{\sigma}{0}\end{array}$ & \begin{tabular}{|l}
$\stackrel{g}{\zeta}$ \\
$\grave{n}$ \\
$\sim$ \\
$\sim$
\end{tabular} & $\stackrel{?}{-}$ & হి & $\overline{\dot{m}}$ & & $\begin{array}{l}\infty \\
\stackrel{2}{r}\end{array}$ & $\begin{array}{l}0 \\
0 \\
0 \\
-\end{array}$ & $\begin{array}{l}- \\
\dot{\omega} \\
\text { மn }\end{array}$ & $\stackrel{\text { ํ. }}{\sim}$ & જ̆ & $\stackrel{6}{-}$ \\
\hline 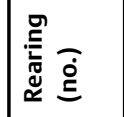 & & $\begin{array}{l}\infty \\
\stackrel{N}{N}\end{array}$ & $\begin{array}{l}\sim \\
\ddot{8} \\
-\end{array}$ & $\mid \begin{array}{l}\infty \\
\infty \\
\infty \\
\stackrel{n}{n} \\
\sim\end{array}$ & $\stackrel{n}{m}$ & $\begin{array}{l}\text { ஜ } \\
\text { જे }\end{array}$ & $\begin{array}{l}\text { Ln } \\
\infty \\
m\end{array}$ & & $\begin{array}{l}\infty \\
\stackrel{\sim}{N}\end{array}$ & ra & $\begin{array}{l}+5 \\
\stackrel{1}{6} \\
6\end{array}$ & $\stackrel{+}{i}$ & 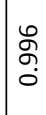 & ণें \\
\hline 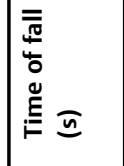 & & $\begin{array}{l}0 \\
\stackrel{\sim}{D} \\
\sim\end{array}$ & $\stackrel{\varphi}{\grave{\sim}}$ & $\begin{array}{l}\hat{n} \\
\dot{0} \\
\frac{1}{m} \\
0\end{array}$ & $\stackrel{m}{\sim}$ & $\begin{array}{l}\infty \\
\stackrel{0}{0} \\
\end{array}$ & $\begin{array}{l}\infty \\
\text { مें } \\
\text { | }\end{array}$ & & $\begin{array}{l}0 \\
\stackrel{\sim}{D} \\
\stackrel{N}{n}\end{array}$ & $\begin{array}{l}0 \\
\bar{\sim}\end{array}$ & $\begin{array}{l}\hat{\infty} \\
\infty \\
\stackrel{1}{r}\end{array}$ & $\stackrel{+}{-}$ & $\begin{array}{l}\text { นू } \\
\text { م़ }\end{array}$ & ì \\
\hline$\sum_{\text {i }}^{0}$ & $\mid \begin{array}{c}\frac{\pi}{E} \\
\bar{n} \\
\frac{\pi}{\alpha} \\
\frac{\pi}{2}\end{array}$ & 惫 & ن & 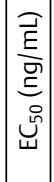 & $>$ & $\approx$ & $\frac{\cup}{\alpha}$ & $\frac{5}{\frac{5}{\pi}}$ & & ن & ن & $>$ & $\approx$ & $\frac{U}{<}$ \\
\hline
\end{tabular}

PLGA-NP), and tween 80-coated NGN-loaded PLGA nanoparticles (tween 80-NGN-PLGA-NP) after induction with ASD at the dose of $25 \mathrm{mg} / \mathrm{kg}$, administered thrice daily ( 8 hourly). Starting from the second day of experiment till $21^{\text {st }}$ day, NGN, as well as its lyophilized nanoparticles, were administered after suspension in $0.5 \%$ $\mathrm{w} / \mathrm{v}$ sodium carboxymethylcellulose, thrice daily.

On the $22^{\text {nd }}$ day, blood samples were taken, $8 \mathrm{~h}$ after the last dose on the $21^{\text {st }}$ day, and plasma was separated for estimating the concentration of NGN as well as levels of TNF- $\alpha$, MMP-9, and HSP-70. The behavioral tests such as rotarod (sensorimotor dysfunction), actophotometer (locomotion), open-field (anxiety), reciprocal social interaction, and repetitive self-grooming were performed, and the animals were sacrificed under deep anesthesia. The brains were excised and analyzed for concentration of NGN as well as TNF- $\alpha$ and P-gp concentrations.

\section{Behavioral tests and neuroinflammatory biomarkers}

ASD is associated with core symptoms such as the inability to socially interact and repetitive behavior, whereas sensorimotor dysfunction changes in locomotor activity and anxiety are some of the associated behaviors occurring in ASD. Hence, in order to establish a PK-PD model for understanding the effect of treatment with various doses of NGN and its coated and uncoated nanocarriers, the following behavioral tests were conducted and biomarkers were evaluated. Details of the behavioral tests are given in the Supporting Information (section S1).

\section{Behavioral tests}

Briefly, associated behaviors like sensorimotor dysfunction, locomotor activity, and anxiety were assessed by rotarod test [47], actophotometer [48], and open-field test [49], respectively. Neurobehavioral tests for core autistic behaviors such as social interaction ability and repetitive behavior were assessed by reciprocal social interaction test [50] and repetitive self-grooming [51], respectively.

These tests were conducted $8 \mathrm{~h}$ after the administration of the last dose.

\section{Neuroinflammatory biomarkers and concentration of P-gp at BBB as pharmacodynamic parameters}

ELISA assay was conducted to analyze neuroinflammatory biomarkers such as TNF- $\alpha$, MMP-9, and HSP-70 using the rat plasma; however, levels of TNF- $\alpha$ were also assessed in brain homogenate. These were assessed using a rat TNF- $\alpha$ kit (R\&D Systems) and quantikine MMP-9 (R\&D Systems). HSP-70 was estimated to assay the level of HSP-70 in plasma (Qayee Biotechnology) and concentration of P-gP in the brain samples were determined by rat P-gp kit (Wuhan Sciences). P-gp concentration was assessed in brain homogenate as neuroinflammation leads to upregulation of P-gp.

\section{Blood sampling and brain tissue collection}

Thirty-five Sprague-Dawley rats were randomly divided into 7 groups with 5 animals in each group. Five-hundred-microliter blood samples were collected $8 \mathrm{~h}$ after the last dose on the $21^{\text {st }}$ day by retro-orbital venous plexus puncture under mild ether anesthesia. The samples were collected in heparinized tubes and plasma was separated by centrifugation at 10,000 rpm for $10 \mathrm{~min}$. Brain samples were collected by cervical dislocation after the behavioral 
tests. Both plasma and brain samples were stored at $-80^{\circ} \mathrm{C}$ for further analysis.

\section{Estimation of NGN in plasma and brain using RP- HPLC method}

A simple, sensitive, robust, and effective reversed phase (RP)-HPLC method was developed with some modifications and validated in our laboratory for detection and quantification of NGN in plasma and brain [52].

\section{PK-PD modeling}

The onset, intensity, and duration of pharmacological effect of the drug depend on the dose and pharmacokinetics of the drug, which determines drug concentration in plasma as well as a receptor site. We applied sigmoid $\mathrm{E}_{\max }$ model [35] to study the relationship between the concentration of NGN in plasma and pharmacological effects like sensorimotor dysfunction, locomotor activity, anxietylike behavior, reciprocal social interaction, repetitive self-grooming, and TNF- $\alpha$, MMP-9, and HSP-70 levels. The same model was applied to study the relationship between the concentration of NGN in the brain and above-mentioned pharmacological effects except for MMP-9 and HSP-70. Also, the concentration of P-gP at the blood-brain barrier was considered.

\section{Sigmoid $\mathrm{E}_{\max }$ model}

This model, a generalization of the $E_{\max }$ model, is based on the observation that an increase in drug concentration near maximum pharmacologic response produces a disproportionately smaller increase in pharmacologic response. This model has been derived from the theory of drug-receptor interaction. The sigmoid $E_{\max }$ model, like the $E_{\max }$ model, describes drug action in terms of maximum effect $\left(E_{\max }\right)$ and $E C_{50}$ (the drug concentration that produces $50 \%$ of $\left.E_{\max }\right)$. The equation for the sigmoid $E_{\max }$ model is

$\mathrm{E}=\frac{\mathrm{E}_{\max } \times \mathrm{C}^{\gamma}}{\mathrm{EC}_{50}+\mathrm{C}^{\gamma}}+\mathrm{E}_{0}$

where $E_{0}$ represents the value of $E$ when no drug is present. The exponent $\gamma$ is the sigmoid factor or steepness of the curve; $\gamma=1$ for the hyperbolic curve, $\gamma>1$ for steeper curve, and $\gamma<1$ for a smoother curve. A very large $y$ value may indicate allosteric or cooperative effect in the interaction of the drug molecules with the receptor.

In order to study PK-PD correlation, 3 doses (25, 50, and $100 \mathrm{mg} /$ $\mathrm{kg}$ ) of unencapsulated NGN and 3 doses consisting of different formulations, namely uncoated NGN nanoparticles $(25 \mathrm{mg} / \mathrm{kg}$ ) as well as GSH and tween 80 -coated NGN nanoparticles, $(25 \mathrm{mg} / \mathrm{kg}$ ) were administered, which resulted in 6 different concentrations of NGN in plasma and brain. Our pharmacokinetic study (unpublished data) indicated that the peak plasma concentration of NGN after the administration of free NGN $(25 \mathrm{mg} / \mathrm{kg})$ was $4227.08 \pm 0.52 \mathrm{ng} / \mathrm{mL}$. The peak plasma concentrations of NGN were significantly enhanced after administration of NGN-PLGA nanoparticles ( $5325.057 \pm 0.57 \mathrm{ng} / \mathrm{mL}$ ) and were further increased as a result of their surface modification with GSH $(6323.09 \pm 0.415 \mathrm{ng} / \mathrm{mL})$ and tween $80(6189.05 \pm 0.305 \mathrm{ng} / \mathrm{mL})$. Brain concentration was also
1.63 times and 1.39 times enhanced after administration of GSH and tween 80-coated nanocarriers as compared to uncoated nanocarriers. Also, from our previous pharmacokinetic studies (unpublished data), it was observed that half-life for coated as well as uncoated NGN-loaded PLGA nanoparticles is approximately $4 \mathrm{~h}$, whereas for free NGN, the half-life is approximately $2.6 \mathrm{~h}$. Therefore, in case of nanoparticles, the minimum residual dose on the $22^{\text {nd }}$ day ( $8 \mathrm{~h}$ after the last dose on $21^{\text {st }}$ day) would be a higher proportion of the $C_{\max }$ of the corresponding dose as compared to unencapsulated NGN. Thus, plasma and brain concentrations of NGN vary with different doses of NGN (unencapsulated) and coated as well as uncoated nanocarriers resulting in 6 different concentrations. The pharmacodynamic parameters were measured for all the above 6 dosage forms.

\section{Acknowledgments}

Research grants sanctioned by SERB, Department of Science \& Technology (grant no. SB/FT/LS-284/2012), All India Council of Technical Education (11-25/RIFD/CAYT/POL-II/2013-14), and University Grants Commission (20-29(12)/2012(BSR), New Delhi to Dr. Anurag Kuhad are gratefully acknowledged. Senior Research Fellowship sanctioned by Indian Council of Medical Research (45/13/2014-Nan/BMS), New Delhi to Ms. Ranjana Bhandari is also gratefully acknowledged.

\section{Conflicts of Interest}

The authors declare no conflicts of interest.

\section{References}

[1] American Psychiatric Association. Diagnostic and Statistical Manual of Mental Disorders. American Psychiatric Association; 2013 Accessed at http://www.psychiatryonline.org/doi/book/10.1176/appi. books.9780890425596

[2] Estabillo JA, Matson JL, Cervantes PE. Autism symptoms and problem behaviors in children with and without developmental regression. J Dev Phys Disabil 2018; 30: 17-26

[3] World Health Organization. Autism spectrum disorders. 2017; Accessed at, http://www.who.int/mediacentre/factsheets/autismspectrum-disorders/en/

[4] Holt R, Monaco AP. Links between genetics and pathophysiology in the autism spectrum disorders. EMBO Mol Med 2011; 3: 438-450

[5] Santangelo SL, Tsatsanis K. What is known about autism: genes, brain, and behavior. Am J Pharmacogenomics 2005; 5: 71-92

[6] Newschaffer C], Croen LA, Daniels J, Giarelli E, Grether JK, Levy SE, Mandell DS, Miller LA, Pinto-Martin J, Reaven J, Reynolds AM, Rice CE, Schendel D, Windham GC. The epidemiology of autism spectrum disorders. Annu Rev Public Health 2007; 28: 235-258

[7] EJH Jones, Gliga T, Bedford R, Charman T, Johnson MH. Developmental pathways to autism: a review of prospective studies of infants at risk. Neurosci Biobehav Rev 2014; 39: 1-33

[8] LaSalle JM. Epigenomic strategies at the interface of genetic and environmental risk factors for autism. J Hum Genet 2013; 58: 396-401 
[9] Modabbernia A, Velthorst E, Reichenberg A. Environmental risk factors for autism: an evidence-based review of systematic reviews and meta-analyses. Mol Autism 2017; 8: 13

[10] Ciernia AV, Laufer BI, Dunaway KW, Mordaunt CE, Coulson RL, Yasui $\mathrm{DH}$, LaSalle JM. Epigenomic convergence of genetic and immune risk factors in autism brain. bioRxiv 270827; doi: https://doi.org/10.1101/ 270827; Accessed at: https://www.biorxiv.org/content/10.1101/ 270827v2

[11] Rossignol DA, Frye RE. A review of research trends in physiological abnormalities in autism spectrum disorders: Immune dysregulation, inflammation, oxidative stress, mitochondrial dysfunction and environmental toxicant exposures. Mol Psychiatry 2012; 17: 389-401

[12] Nadeem A, Ahmad SF, Attia SM, Bakheet SA, Al-Harbi NO, AL-Ayadhi LY. Activation of IL-17 receptor leads to increased oxidative inflammation in peripheral monocytes of autistic children. Brain Behav Immun 2018; 67: 335-344

[13] Vargas DL, Nascimbene C, Krishnan C, Zimmerman AW, Pardo CA. Neuroglial activation and neuroinflammation in the brain of patients with autism. Ann Neurol 2005; 57: 67-81

[14] Bjorkland G, Saad K, Chirumbolo S, Kern JK, Geier DA, Geier MR, Urbina MA. Immune dysfunction and neuroinflammation in autism spectrum disorder. Acta Neurobiol Exp 2016; 76: 257-268

[15] Jyonouchi H, Sun S, Itokazu N. Innate immunity associated with inflammatory responses and cytokine production against common dietary proteins in patients with autism spectrum disorder. Neuropsychobiology 2002; 46: 76-84

[16] Horvath K, Papadimitriou JC, Rabsztyn A, Drachenberg C, Tildon JT. Gastrointestinal abnormalities in children with autistic disorder. J Pediatr 1999; 135: 559-563

[17] MacFabe DF, Cain DP, Rodriguez-Capote K, Franklin AE, Hoffman JE, Boon F, Taylor AR, Kavaliers M, Ossenkopp KP. Neurobiological effects of intraventricular propionic acid in rats: Possible role of short chain fatty acids on the pathogenesis and characteristics of autism spectrum disorders. Behav Brain Res 2007; 176: 149-169

[18] Choi J, Lee S, Won J, Jin Y, Hong Y, Hur TY, Kim JH, Lee SR, Hong Y. Pathophysiological and neurobehavioral characteristics of a propionic acid-mediated autism-like rat model. PLoS One 2018; 13: e0192925

[19] Bhandari R, Kuhad A. Neuropsychopharmacotherapeutic efficacy of curcumin in experimental paradigm of autism spectrum disorders. Life Sci 2015; 141: 156-169

[20] Bhandari R, Kuhad A. Resveratrol suppresses neuroinflammation in the experimental paradigm of autism spectrum disorders. Neurochem Int 2017; 103: 8-23

[21] Bhandari R, Paliwal JK, Kuhad A. Naringenin and its nanocarriers as potential phytotherapy for autism spectrum disorders. J Funct Foods 2018; 47: 361-375

[22] Felgines C, Texier O, Morand C, Manach C, Scalbert A, Régerat F, Rémésy $C$. Bioavailability of the flavanone naringenin and its glycosides in rats. Am J Physiol Gastrointest Liver Physiol 2000; 279: G1148-G1154

[23] Kumar S, Tiku AB. Biochemical and molecular mechanisms of radioprotective effects of naringenin, a phytochemical from citrus fruits. J Agric Food Chem 2016; 64: 1676-1685

[24] Nahmias Y, Goldwasser J, Casali M, Van Poll D, Wakita T, Chung RT, Yarmush ML. Apolipoprotein B-dependent hepatitis C virus secretion is inhibited by the grapefruit flavonoid naringenin. Hepatology 2008; 47 : 1437-1445

[25] Yi LT, Liu B Bin, Li ], Luo L, Liu Q, Geng D, Tang Y, Xia Y, Wu D. BDNF signaling is necessary for the antidepressant-like effect of naringenin. Prog Neuro-Psychopharmacology. Biol Psychiatry 2014; 48: 135-141

[26] Wu LH, Lin C, Lin HY, Liu YS, Wu CY], Tsai CF, Chang PC, Yeh WL, Lu DY. Naringenin suppresses neuroinflammatory responses through inducing suppressor of cytokine signaling 3 expression. Mol Neurobiol 2016; 53: 1080-1091
[27] Birt DF, Hendrich S, Wang W. Dietary agents in cancer prevention: flavonoids and isoflavonoids. Pharmacol Ther 2001; 90: 157-177

[28] Ratnam DV, Ankola DD, Bhardwaj V, Sahana DK. Kumar MNVR. Role of antioxidants in prophylaxis and therapy: A pharmaceutical perspective. J Control Release 2006; 113: 189-207

[29] Yen FL, Wu TH, Lin LT, Cham TM, Lin CC. Naringenin-loaded nanoparticles improve the physicochemical properties and the hepatoprotective effects of naringenin in orally-administered rats with $\mathrm{CCl}(4)$-induced acute liver failure. Pharm Res 2009; 26: 893-902

[30] Chien JY, Friedrich S, Heathman MA, de Alwis DP, Sinha V. Pharmacokinetics/pharmacodynamics and the stages of drug development: role of modeling and simulation. AAPS J 2005; 7: E544-E559

[31] Danhof M, de Lange ECM, Della Pasqua OE, Ploeger BA, Voskuyl RA. Mechanism-based pharmacokinetic-pharmacodynamic (PK-PD) modeling in translational drug research. Trends Pharmacol Sci 2008; 29: 186-191

[32] Meibohm B, Derendorf H. Basic concepts of pharmacokinetic/ pharmacodynamic (PK/PD) modelling. Int J Clin Pharmacol Ther 1997 35: 401-413

[33] Wright DFB, Winter HR, Duffull SB. Understanding the time course of pharmacological effect: a PKPD approach. Br J Clin Pharmacol 2011; 71: 815-823

[34] Khan DD, Friberg LE, Nielsen El. A pharmacokinetic-pharmacodynamic (PKPD) model based on in vitro time-kill data predicts the in vivo PK/ PD index of colistin. J Antimicrob Chemother 2016; 71: 1881-1884

[35] Shargel L, Wu-Pong S, Yu ABC. Applied Biopharmaceutics \& Pharmacokinetics. $5^{\text {th }}$ ed New York: McGraw-Hill Medical; 2005: 527-563

[36] MacFabe DF, Rodríguez-Capote K, Hoffman JE, Franklin AE, Mohammad-Asef Y, Taylor AR, Boon F, Cain DP, Kavaliers M, Possmayer F, Ossenkopp KP. A novel rodent model of autism: intraventricular infusions of propionic acid increase locomotor activity and induce neuroinflammation and oxidative stress in discrete regions of adult rat brain. Am J Biochem Biotechnol 2008; 4: 146-166

[37] El-Ansary AK, Bacha A Ben, Kotb M. Etiology of autistic features: the persisting neurotoxic effects of propionic acid. J Neuroinflammation 2012; 9: 661

[38] Shultz SR, Macfabe DF, Martin S, Jackson ], Taylor R, Boon F, Ossenkopp KP, Cain DP. Intracerebroventricular injections of the enteric bacterial metabolic product propionic acid impair cognition and sensorimotor ability in the Long-Evans rat: Further development of a rodent model of autism. Behav Brain Res 2009; 200: 33-41

[39] Abdallah MW, Michel TM. Matrix metalloproteinases in autism spectrum disorders. J Mol Psychiatry 2013; 1: 16

[40] González-Fraguela ME, Hung MD, Vera H, Maragoto C, Noris E, Blanco L, Galvizu R, Robinson M. Oxidative stress markers in children with autism spectrum disorders. British J Med Res 2013; 3: 307-317

[41] Wu LH, Lin C, Lin HY, Liu YS, Wu CY], Tsai CF, Chang PC, Yeh WL, Lu DY. Naringenin suppresses neuroinflammatory responses through inducing suppressor of cytokine signaling 3 expression. Mol Neurobiol 2016; 53: 1080-1091

[42] Wilson B, Samanta MK, Santhi K, Kumar KPS, Paramakrishnan N, Suresh B. Targeted delivery of tacrine into the brain with polysorbate 80-coated poly(n-butylcyanoacrylate) nanoparticles. Eur J Pharm Biopharm 2008; 70: 75-84

[43] Jain A, Jain A, Garg NK, Tyagi RK, Singh B, Katare OP, Webster T], Soni V. Surface engineered polymeric nanocarriers mediate the delivery of transferrin-methotrexate conjugates for an improved understanding of brain cancer. Acta Biomater 2015; 24: 140-151

[44] Grover A, Hirani A, Pathak Y, Sutariya V. Brain-targeted delivery of docetaxel by glutathione-coated nanoparticles for brain cancer. AAPS PharmSciTech 2014; 15: 1562-1568 
[45] Geldenhuys W, Mbimba T, Bui T, Harrison K, Sutariya V. Brain-targeted delivery of paclitaxel using glutathione-coated nanoparticles for brain cancers. J Drug Target 2011; 19: 837-845

[46] Fessi H, Puisieux F, Devissaguet JP, Ammoury N, Benita S. Nanocapsule Formation by interfacial polymer deposition following solvent displacement. Int J Pharm 1989; 55: R1-R4

[47] Dunham NW, Myua TS. A note on a simple apparatus for detecting neurological deficit in rats and mice. J Am Pharm Assoc Am Pharm Assoc (Baltim) 1957; 46: 208-209

[48] Sachdeva AK, Kuhad A, Chopra K. Epigallocatechin gallate ameliorates behavioral and biochemical deficits in rat model of load-induced chronic fatigue syndrome. Brain Res Bull 2011; 86: 165-172

[49] Raghavendra V, Chopra K, Kulkarni SK. Brain renin angiotensin system (RAS) in stress-induced analgesia and impaired retention. Peptides 1999; 20: 335-342
[50] Silverman JL, Yang M, Lord C, Crawley JN. Behavioural phenotyping assays for mouse models of autism. Nat Rev Neurosci 2010; 11: 490-502

[51] Moretti P, Bouwknecht JA, Teague R, Paylor R, Zoghbi HY. Abnormalities of social interactions and home-cage behavior in a mouse model of Rett syndrome. Hum Mol Genet 2005; 14: 205-220

[52] Bhandari R, Kuhad A, Paliwal JK, Kuhad A. Development of a new, sensitive, and robust analytical and bio-analytical RP- HPLC method for in vitro and in vivo quantification of naringenin in polymeric nanocarriers. J Anal Sci Technol 2019; 10: 11 